\title{
AdDREssing RemitTing BehaVior Using AN Ordinal CLASSIfICATION APPROACH
}

\author{
IWINAC'13 \\ 5TH. INTERNATIONAL WORK-CONFERENCE ON THE \\ INTERPLAY BETWEEN NATURAL AND ARTIFICIAL COMPUTATION
}

\author{
P. Campoy-Muñoz \\ Universidad Loyola Andalucía \\ P.A. Gutiérrez \& C. Hervás Martínez \\ AYRNA Research Group: http://www.uco.es/ayrna \\ Universidad de Córdoba \\ June 12, 2013
}




\section{Outline}

\begin{tabular}{|l|l|}
\hline 1 & THE PROBLEM \\
\hline 2 & OUR PROPOSAL \\
\hline 3 & EXPERIMENTAL DESIGN \\
\hline 4 & RESULTS \\
\hline $\mathbf{5}$ & CONCLUSSIONS \\
\hline
\end{tabular}




\section{The Problem}

REMITTANCES: transfers made by migrants who are employed and have lived, at least one year, in other economies.

Worldwide

Developing countries

Top 10 recipients of migrant remittances

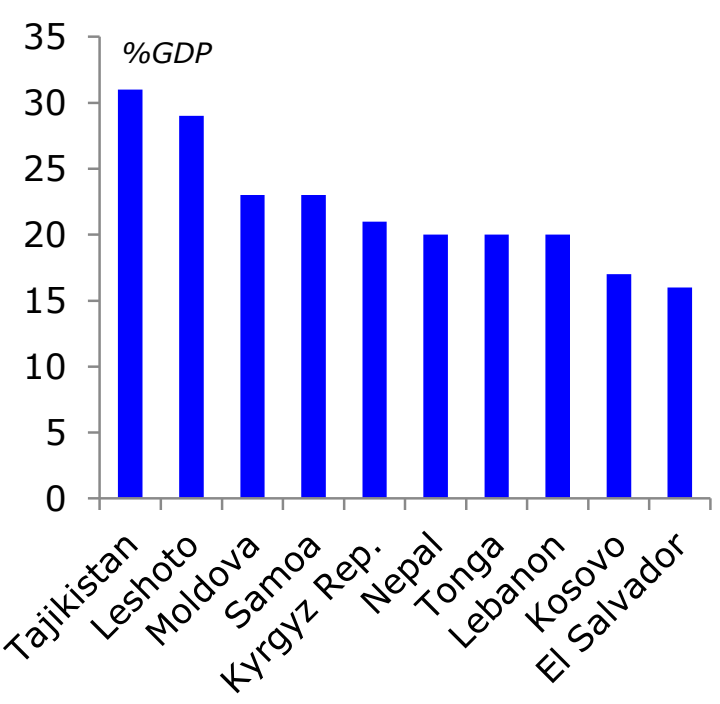

$215 \mathrm{MM}$ immigrants $\Leftrightarrow 501.000 \mathrm{MM}$ US\$

$171 \mathrm{MM}$ immigrants $\Leftrightarrow 372.000 \mathrm{MM}$ US\$

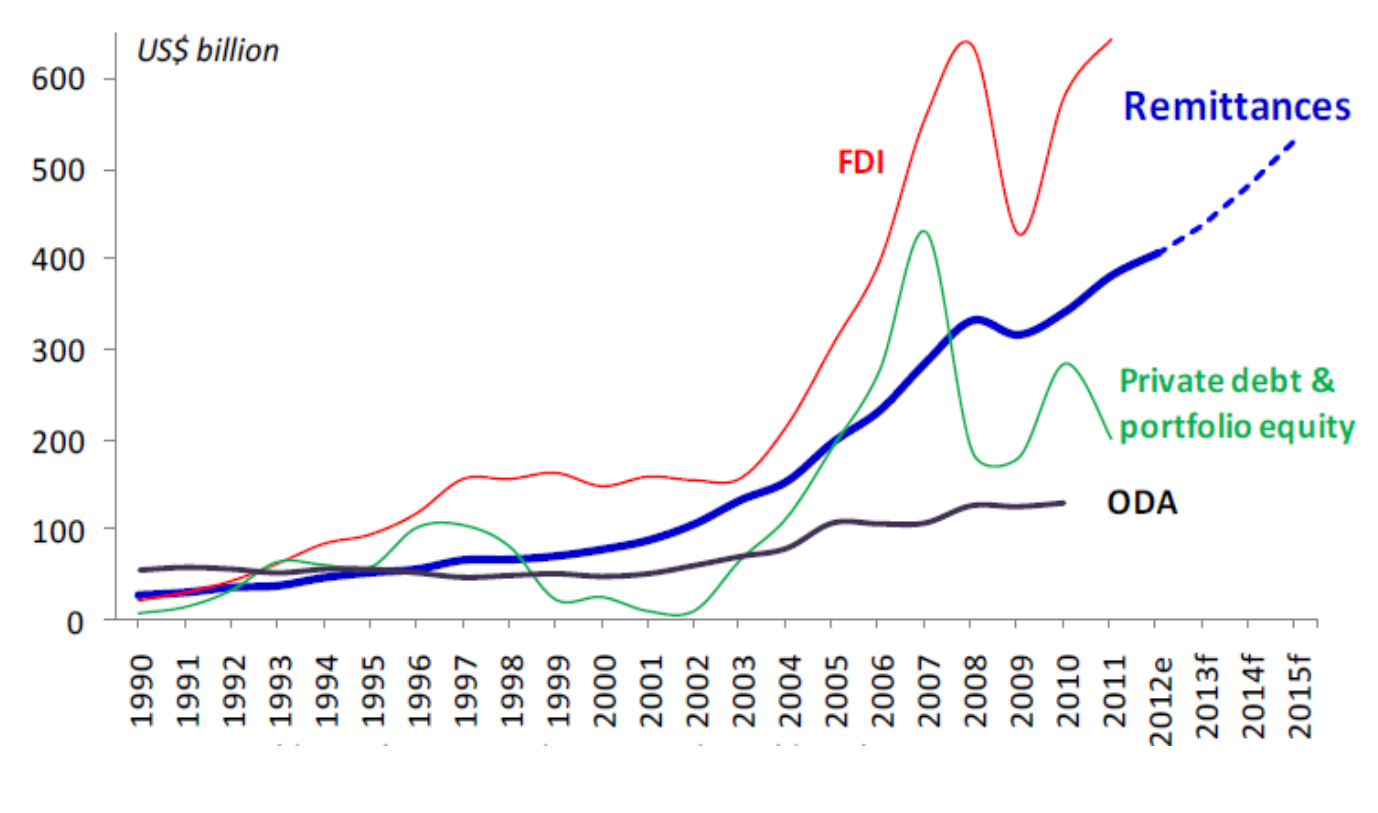




\section{The Problem}

REMITTANCES: transfers made by migrants who are employed and have lived, at least one year, in other economies.

Worldwide

Developing countries

Top 10 recipients of migrant remittances

\section{$215 \mathrm{MM}$ immigrants}

$171 \mathrm{MM}$ immigrants
$\Leftrightarrow 501.000$ MM US\$

$\Leftrightarrow 372.000$ MM US\$

\section{Country level $\rightarrow$ Improving macroeconomic stability}

Household level $\rightarrow$ Reducing the depth and severity of poverty
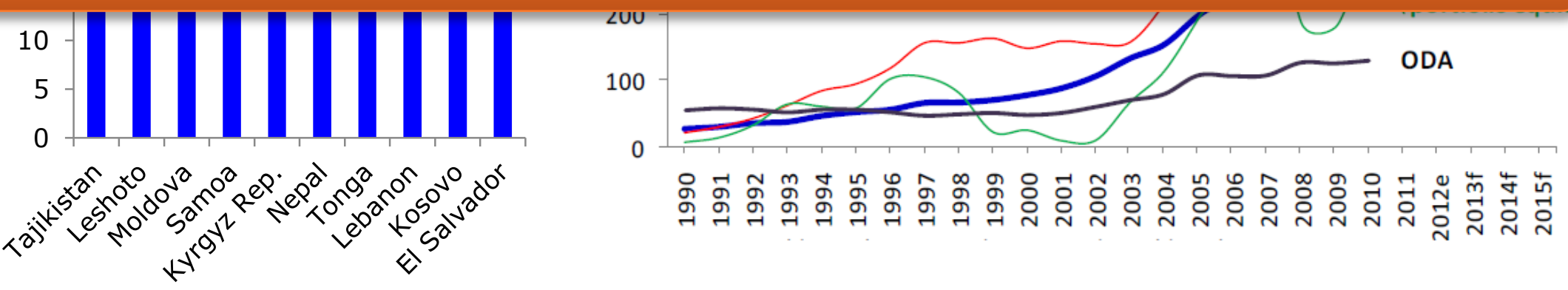


\section{The Problem}

WHY DO SOME MIGRANTS SEND

MUCH (LESS) MONEY THAN OTHERS?

$f: X \rightarrow Y$

$$
x \in X \subseteq R^{k} \quad \begin{gathered}
\text { Immigrants' } \\
\text { characteristics }
\end{gathered}
$$

$$
y \in Y=\left\{C_{1}, C_{2}, \ldots, C_{Q}\right\} \quad \begin{gathered}
\text { Remittance } \\
\text { levels }
\end{gathered}
$$

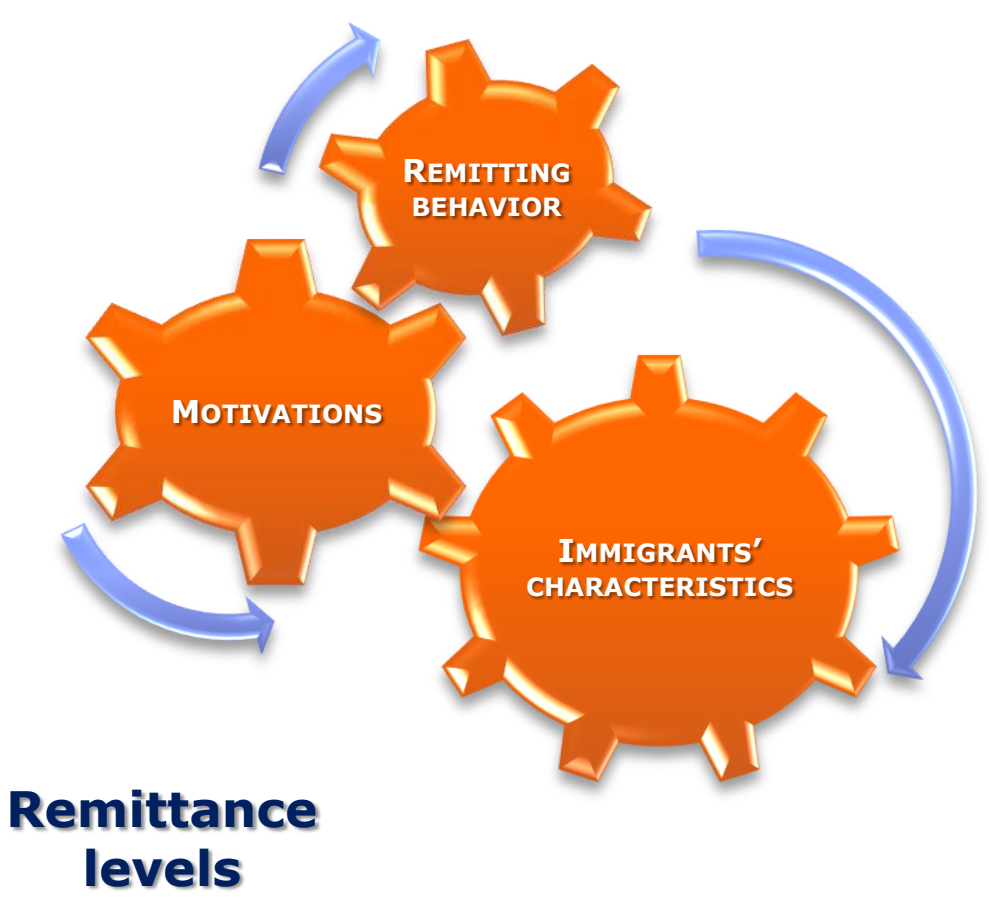

TRADITIONAL APPROACH $\Rightarrow$ Ordinal regression (logit and probit models) - Learn a rule to predict categories or labels in an ordinal scale. -The labels are discrete, but there is a natural order among them.

Performance can be hampered by the assigning of numerical values because the distance between classes are unknown 


\section{OUR Proposal}

\section{CLASSIFICATION APPROACH $\gg$ Machine Learning Methods}

-An algorithm extracts information given a group of label data in order to be able of predicting the label of new unseen data

$f: X \rightarrow Y$

$$
x \in X \subseteq R^{k} \quad \begin{gathered}
\text { Immigrants' } \\
\text { characteristics }
\end{gathered}
$$

$$
y \in Y=\left\{C_{1} \prec C_{2} \prec \ldots \prec C_{Q}\right\} \begin{gathered}
\text { Remittance } \\
\text { levels }
\end{gathered}
$$

ORDINAL CLASSIFIERS
Remitting behaviour would be an ordinal outcome, as other economic behaviors (saving, investment, credit consume...)

$$
y \in Y=\left\{C_{1}, C_{2}, \ldots, C_{Q}\right\} \quad \begin{gathered}
\text { Remittance } \\
\text { levels }
\end{gathered}
$$

NOMINAL CLASSIFIERS
A posteriori definition of the target variable makes its application suitable 


\section{OUR Proposal}

\section{ORdinal Classifiers $\Rightarrow$ Support Vector Machine Approach}

-Trying to find the optimal pararell separating hyperplane $f(\mathbf{w}, \mathbf{x}, b)=\mathbf{w} \cdot \mathbf{x}+b$

- To construct the decision function $y_{i}=\operatorname{sign}(f(\mathbf{w}, \mathbf{x}, \mathrm{b})), x_{i} \in \mathrm{X}, y_{i} \in \mathrm{Y}\{-1,1\}$

- The introduction of slack-variables $\xi_{i}$ relax the hard-margin constrain, allowing to deal with non-separable sets

\section{Support Vector Machine With ORdered Partitions (SVMOP)}

-Q-1 binary SVM classifiers

-Consider the ordinal nature by comparison between the label of a pattern and a given rank $k \rightarrow y_{q i}=-1, \forall q<k$ and $y_{q i}=+1, \forall q \geq k$ -Explicit weights are imposed over the patterns -Decision of the different binary classifiers were combined by using associated probabilities, $p_{q}=P\left(y C_{q} \mid \mathbf{x}\right), 1 \leq q \leq Q-1$. 


\section{OUR Proposal}

\section{Ordinal Classifiers $\Rightarrow$ Support Vector Machine Approach}

\section{SUPPORT VECTOR MACHINE FOR ORDINAL REgRESSION WITH EXPLICIT CONSTRAINT (SVOREX)}

-Assuming the ordinal response variable is the indicator of an unobserved continuous variable

-A function $f(\mathbf{x})$ that predicts the real-valued outcomes

-A threshold vector $\mathbf{b} \in \mathrm{R}^{J-1}$ to represent the intervals in the range of $f(\mathbf{x})$, where $b_{1} \leq b_{2} \leq \ldots \leq b_{J-1}$.

-The SVOREX parallel separating hyperplanes with the same normal vector $\mathbf{w}$ but different thresholds $b_{j}$. 


\section{OUR Proposal}

\section{Performance evaluation}

CONTINGENCY OR CONFUSION MATRIX $M(f)$ in a classification problem with $Q$ classes and $N$ training or testing patterns:

$$
M(f)=\left\{n_{i j} ; \sum_{i j=1}^{Q} n_{i j}=N\right\}
$$

where $n_{i j}$ represents the number of times the patterns are predicted by classier $f$ to be in class $j$ when they really belong to class $i$.

\section{METRICS}

$C C R=\frac{1}{N} \sum_{i=1}^{Q} I\left(y_{i}^{*}=y_{i}\right)$

$S_{q}=\frac{n_{q q}}{n_{q}}$

$M A E=\frac{1}{N} \sum_{i=1}^{N}\left|O\left(y_{i}\right)-O\left(y_{i}^{*}\right)\right|$
Correct Clasification Rate $\Rightarrow$ Percentage of immigrants for which the remittance level (class) is correctly predicted

Sensitivity of $q$-th class $\Rightarrow$ Percentage of immigrants well classified within each class

Mean Absolute Error $\Rightarrow$ Deviation of the predicted class with respect to the real one 


\section{EXPERIMENTAL DESIGN}

\section{DATASET DESCRIPTION}

National Immigration Survey (NIS-2007) carried out by Spanish

Statistical Institute

$-15,465$ foreing borns, aged 16 or over and residing in Spain for at least 1 year

-About 250 variables cover several issues of immigrants' life in Spain.

\section{Sample evidence:}

-Ecuadorian immigrants (599 individuals), one of the largest collective

- 21 variables related to remitting behaviour, grouped into 5 sets: socioeconomic variables, labor market situation, linkages with home country $(\mathrm{HC})$, migratory strategy and remittances information.

-Target variable: the amount of remittances sent overseas during the last year 


\section{EXPERIMENTAL DESIGN}

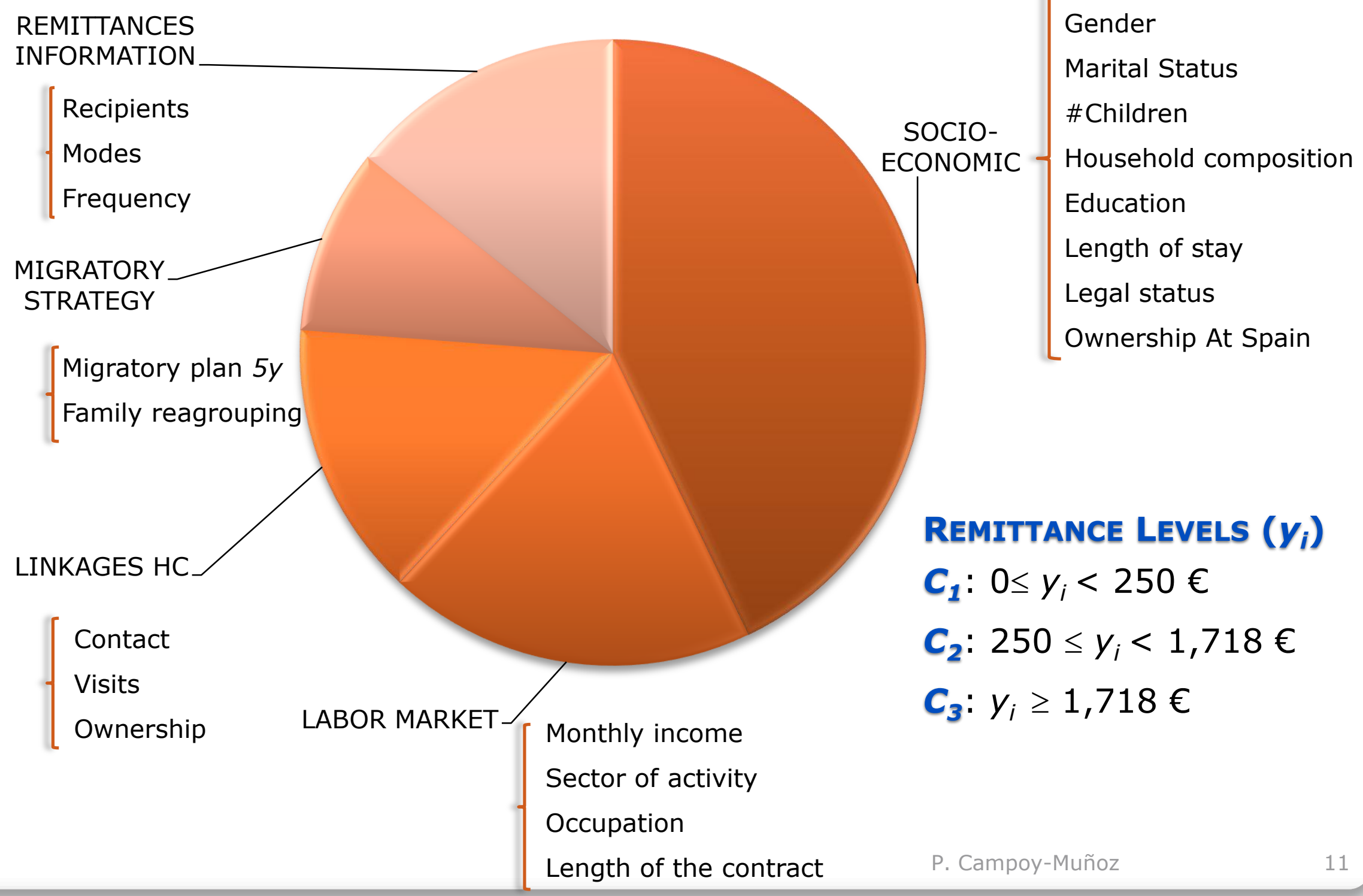




\section{EXPERIMENTAL DESIGN}

\begin{tabular}{|c|c|c|c|}
\hline & \multicolumn{2}{|r|}{ CLASIFFIERS } & SOFTWARE \\
\hline \multirow{2}{*}{$\begin{array}{l}\text { LOGISTIC- } \\
\text { BASED }\end{array}$} & \multirow{5}{*}{ 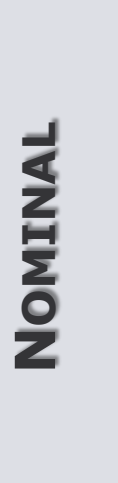 } & MLOGISTIC & \\
\hline & & SLOGISTIC & WEKA \\
\hline \multirow{3}{*}{$\begin{array}{c}\text { ARTIFICIAL } \\
\text { NEURAL } \\
\text { NETWORKS }\end{array}$} & & Multilayer Perceptron Network (MLP) & WEKA \\
\hline & & Radial Basis Function Network (RBE) & \\
\hline & & Support Vector Machine (SVE1v1) & \\
\hline \multirow{2}{*}{$\begin{array}{l}\text { SUPPORT } \\
\text { VECTOR } \\
\text { MACHINE }\end{array}$} & \multirow{2}{*}{$\frac{1}{\frac{1}{4}}$} & $\begin{array}{l}\text { Support Vector Mach:ine with Ordered } \\
\text { Partitions (SVMSP) }\end{array}$ & MATLAB \\
\hline & & \multicolumn{2}{|c|}{$\begin{array}{l}\text { Support Vector Machine for Ordinal } \\
\text { Regrsssion with Explicit Constraint SVOREX) }\end{array}$} \\
\hline & & \multirow{2}{*}{\multicolumn{2}{|c|}{$\begin{array}{l}\text {-10-fold cross-validation } \\
\text { - Nested } 5 \text {-fold cross-validation (over training set) to } \\
\text { adjust hyperparameter values } C \in\left\{10^{-3}, 10^{-2}, \ldots, 10^{3}\right\} ; \sigma \\
\in\left\{10^{-3}, 10^{-2}, \ldots, 10^{3}\right\}\end{array}$}} \\
\hline \multicolumn{2}{|c|}{$\begin{array}{l}\text {-10-fold cross-validation } \\
\text { - Default configuration of } \\
\text { parameter setting }\end{array}$} & & \\
\hline
\end{tabular}




\begin{tabular}{|c|c|c|c|c|c|c|}
\hline Variable set & Classifiers & $C C R$ & $S_{\text {CLASS 1 }}$ & $S_{\text {CLASS } 2}$ & $S_{\text {CLASS } 3}$ & MAE \\
\hline \multirow{7}{*}{$\begin{array}{c}\text { Socio-economic } \\
\text { variables }\end{array}$} & MLogistic & $47,41 \%$ & $43,92 \%$ & $62,03 \%$ & $9,08 \%$ & $65,95 \%$ \\
\hline & Slogistic & $40,05 \%$ & $46,52 \%$ & $42,92 \%$ & $14,07 \%$ & $76,97 \%$ \\
\hline & MLP & $40,72 \%$ & $43,92 \%$ & $42,58 \%$ & $15,08 \%$ & $74,66 \%$ \\
\hline & RBF & $46,41 \%$ & $39,09 \%$ & $61,10 \%$ & $8,62 \%$ & $67,29 \%$ \\
\hline & SVC1V1 & $44,74 \%$ & $33,95 \%$ & $41,16 \%$ & $57,27 \%$ & $68,29 \%$ \\
\hline & SVMOP & $45,74 \%$ & $11,64 \%$ & $64,39 \%$ & $58,77 \%$ & $61,94 \%$ \\
\hline & SVOREX & $44,90 \%$ & $17,46 \%$ & $76,87 \%$ & $40,13 \%$ & $59,44 \%$ \\
\hline \multirow{7}{*}{$\begin{array}{c}\text { Labor market } \\
\text { situation }\end{array}$} & MLogistic & $50,75 \%$ & $48,77 \%$ & $61,47 \%$ & $14,83 \%$ & $62,44 \%$ \\
\hline & Slogistic & $35,89 \%$ & $35,44 \%$ & $47,60 \%$ & $11,11 \%$ & $82,32 \%$ \\
\hline & MLP & $37,38 \%$ & $64,06 \%$ & $30,45 \%$ & $19,74 \%$ & $86,68 \%$ \\
\hline & RBF & $51,42 \%$ & $47,69 \%$ & $65,63 \%$ & $13,38 \%$ & $60,94 \%$ \\
\hline & SVC1V1 & $48,56 \%$ & $46,61 \%$ & $37,13 \%$ & $60,48 \%$ & $64,97 \%$ \\
\hline & SVMOP & $46,25 \%$ & $16,43 \%$ & $57,79 \%$ & $61,97 \%$ & $62,44 \%$ \\
\hline & SVOREX & $47,41 \%$ & $34,53 \%$ & $63,39 \%$ & $44,35 \%$ & $60,27 \%$ \\
\hline \multirow{7}{*}{ Linkages with $\mathrm{HC}$} & MLogistic & $52,75 \%$ & $50,91 \%$ & $65,65 \%$ & $11,09 \%$ & $59,77 \%$ \\
\hline & Slogistic & $43,24 \%$ & $42,34 \%$ & $53,55 \%$ & $8,84 \%$ & $71,12 \%$ \\
\hline & MLP & $38,72 \%$ & $66,17 \%$ & $30,97 \%$ & $18,15 \%$ & $84,34 \%$ \\
\hline & RBF & $52,60 \%$ & $48,77 \%$ & $68,44 \%$ & $11,42 \%$ & $59,93 \%$ \\
\hline & SVC1V1 & $51,75 \%$ & $44,50 \%$ & $40,21 \%$ & $68,42 \%$ & $60,61 \%$ \\
\hline & SVMOP & $48,92 \%$ & $31,75 \%$ & $48,45 \%$ & $64,29 \%$ & $61,77 \%$ \\
\hline & SVOREX & $47,42 \%$ & $33,89 \%$ & $63,34 \%$ & $44,91 \%$ & $59,93 \%$ \\
\hline \multirow{7}{*}{$\begin{array}{c}\text { Migratory } \\
\text { strategy }\end{array}$} & MLogistic & $55,42 \%$ & $53,98 \%$ & $66,56 \%$ & $9,75 \%$ & $55,78 \%$ \\
\hline & Slogistic & $42,07 \%$ & $42,84 \%$ & $53,61 \%$ & $8,50 \%$ & $72,29 \%$ \\
\hline & MLP & $41,55 \%$ & $80,91 \%$ & $30,50 \%$ & $7,04 \%$ & $81,50 \%$ \\
\hline & RBF & $54,42 \%$ & $51,81 \%$ & $68,83 \%$ & $10,66 \%$ & $57,44 \%$ \\
\hline & SVC1V1 & $54,24 \%$ & $58,10 \%$ & $37,53 \%$ & $65,63 \%$ & $56,95 \%$ \\
\hline & SVMOP & $52,91 \%$ & $50,76 \%$ & $38,66 \%$ & $67,49 \%$ & $57,77 \%$ \\
\hline & SVOREX & $50,74 \%$ & $51,75 \%$ & $43,37 \%$ & $56,45 \%$ & $58,11 \%$ \\
\hline \multirow{7}{*}{$\begin{array}{l}\text { Remittaces } \\
\text { information }\end{array}$} & MLogistic & $66,77 \%$ & $79,39 \%$ & $64,65 \%$ & $8,50 \%$ & $36,74 \%$ \\
\hline & Slogistic & $62,61 \%$ & $80,96 \%$ & $62,03 \%$ & $14,62 \%$ & $40,39 \%$ \\
\hline & MLP & $56,58 \%$ & $87,87 \%$ & $52,25 \%$ & $6,59 \%$ & $51,94 \%$ \\
\hline & RBF & $69,29 \%$ & $76,73 \%$ & $70,26 \%$ & $8,36 \%$ & $32,54 \%$ \\
\hline & SVC1V1 & $69,95 \%$ & $75,67 \%$ & $59,24 \%$ & $74,50 \%$ & $32,05 \%$ \\
\hline & SVMOP & $71,13 \%$ & $77,78 \%$ & $65,97 \%$ & $69,91 \%$ & $30,87 \%$ \\
\hline & SVOREX & $69,96 \%$ & $78,30 \%$ & $66,84 \%$ & $65,26 \%$ & $31,37 \%$ \\
\hline
\end{tabular}




\section{RESULTS}

\section{IMMIGRANTS" PROFILES BASED ON SUPPORT VECTORS OF SVMOP CLASSIFIER}

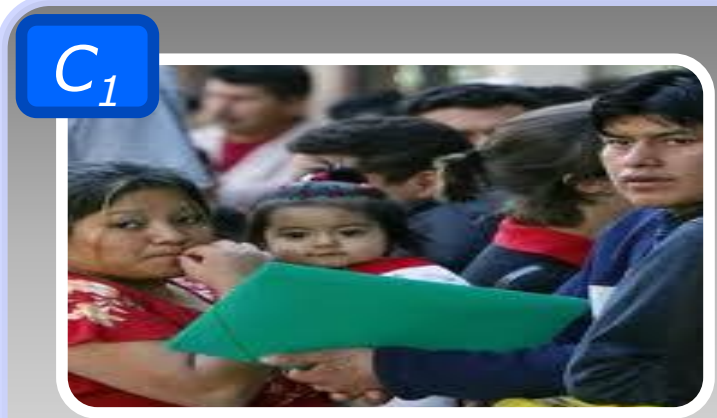

Young individual, secondary education or below

Living with his/her spouse, at least one parents and sometimes one of her children

Longest stay in Spain and higher percentage with legal status

Employed into construction or service sectors

(elementary occupations)

Preference for remaining in Spain but not reagrouping

Remit sometime to parents and children by agency services and to a larger extent only occasionally

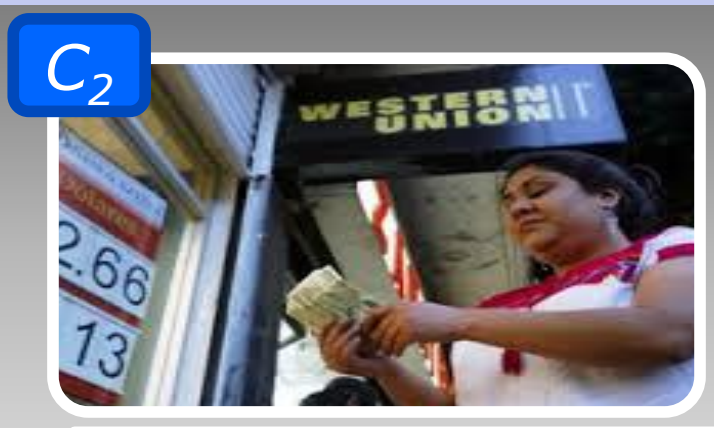

A young woman with secondary studies

Living with her spouse, one of her parents and

sometimes any one of her children

Employed in services sector and household activities

She mainly sent moner back to her parents and to a lesser extent to her children monthly, quarterly or occasionally, especially agency services but also post office service

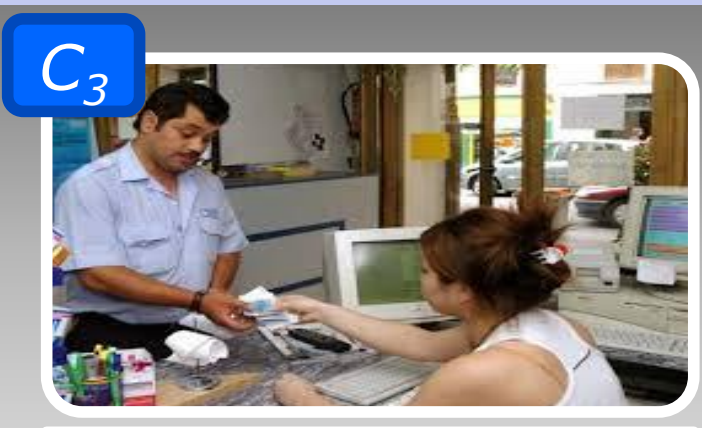

Older man with more than two children

Living with his spouse and to a lesser extent with other family members

He has spent shorter time in Spain compared to the other two groups, but his monthly earnings are the highest

He monthly remits to his parents, as in previous cases, but mostly to his children by using official channels 


\section{CONCLUSSIONS}

The ordinal classifiers allows to predict reasonably well the remittance level according to immigrants" characteristics

Tackling the problem as an ordinal classification task can provide accurate information of the remitting patterns among immigrants

The observed profiles gives us information that can be used to design measures oriented to promote remitting behaviour among immigrants. For example, to facilitate investment at home country for immigrants belonging to class $\mathrm{C} 1$ 


\section{ADDRESSING REMITTING BEHAVIOR USINg AN ORdINAL CLASSIfICATION APPROACH}

THANK YOU FOR YOUR ATTENTION!

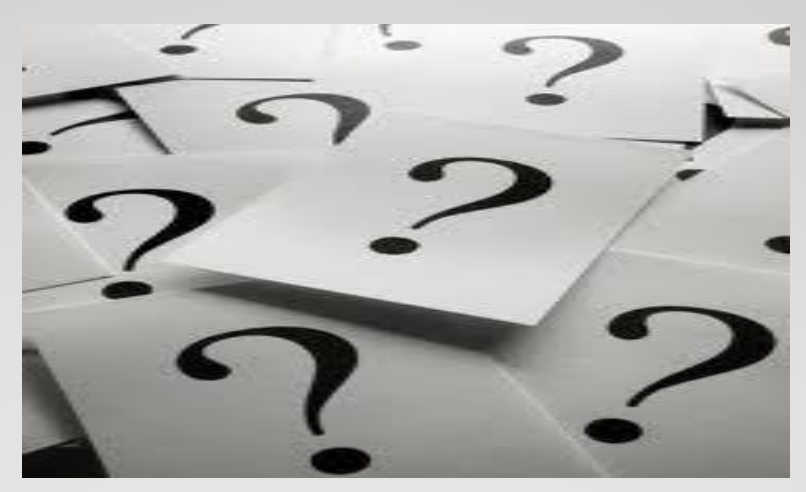

P. Campoy-Muñoz

Universidad Loyola Andalucía

P.A. Gutiérrez \& C. Hervás Martínez

AYRNA Research Group: http://www.uco.es/ayrna

Universidad de Córdoba 